\title{
IAMSE Meeting Report: Student Plenary at the 24th Annual Conference of the International Association of Medical Science Educators
}

\author{
Jayne S. Reuben ${ }^{1}$ (D) William T. Crawley ${ }^{2}$ (D) - Paris Webb ${ }^{1} \cdot$ Koen F. den Brok ${ }^{3}$ Elizabeth Woodburn ${ }^{4}$ (D) \\ Jennifer R. Montemayor ${ }^{2}$ (D) - Sol Roberts-Lieb ${ }^{4}$ (D) Peter G. M. de Jong ${ }^{5}$ (D) $\cdot$ Bonny L. Dickinson ${ }^{6}$ (D)
}

Accepted: 21 September 2020 / Published online: 25 September 2020

(C) International Association of Medical Science Educators 2020, corrected publication 2020

\section{Introduction}

Health professions are rapidly changing in response to advances in technology, modern approaches to information collection and processing, financial pressures, changes in society and demographics, and shifts in political climates. In response to these and other challenges, healthcare providers must become agile and modify their clinical practices to continue to provide exceptional patient care. Importantly, these challenges also need to drive and empower educators to evolve in their approaches to training future providers. Thus, educators not only need to prepare students to practice in current healthcare environments but also must provide a foundation for practice in the rapidly evolving healthcare environments of the future.

While research that gathers students' thoughts, attitudes, and impressions about their education and training is useful, hearing their voices first-hand is essential to identifying and addressing

The 2020 IAMSE Annual Meeting introduced a new program feature: the student plenary. In this session, the student perspective on the meeting theme was highlighted by a panel discussion with four students from different health professions programs. In this meeting report, we provide a brief summary of their presentations.

Bonny L. Dickinson

Dickinson_bl@mercer.edu

1 Texas A\&M University College of Dentistry, Dallas, TX, USA

2 Rocky Vista University College of Osteopathic Medicine, Parker, CO, USA

3 Radboud University Medical Center, Nijmegen, The Netherlands

4 Carle Illinois College of Medicine, Urbana-Champaign, IL, USA

5 Center for Innovation in Medical Education, Leiden University Medical Center, Leiden, The Netherlands

6 Mercer University School of Medicine, Macon, GA, USA their needs to inform curricular change. With this in mind, IAMSE held its first student plenary featuring students studying medicine and dentistry in the Netherlands and the USA. The title of the session was Student Voices: Envisioning the Future of Health Sciences Education Across Different Healthcare Professions Worldwide. The goal of the session was to engage meeting participants in a discussion of how best to prepare students for the healthcare environments of the future. Each presenter gave a 10-min presentation outlining their thoughts about the future of health profession education. An audience question and answer session followed the presentations. The student presentations are summarized below.

\section{Addressing Diversity and Implicit Bias in Medical Education}

\section{William Tyler Crawley, MS4 Student, Rocky Vista University College of Osteopathic Medicine, USA}

The field of medical education has long lagged behind other disciplines when it comes to teaching about diversity. As a result, medical providers are not being adequately taught how disease uniquely affects different populations or how to apply evidence-based medicine to treat diverse patient populations. Implicit bias is another area requiring further attention in medical curricula. We all develop unconscious attitudes and stereotypes that impact our decision-making. These biases are responsible for the incorrect assumptions we hold that can narrow the options provided to our patients with the effect of limiting their ability to make informed decisions about their own healthcare [1]. Research has shown that interpersonal experiences and education can raise awareness of implicit bias, and that this may help to prevent negative impacts on patient care [2].

To address implicit bias, students must partner with educators and institutional officials to change not only what is 
taught but also how it is taught. Educators working with students and experts in the community should identify opportunities to integrate information about diverse patient groups into the medical curriculum. Furthermore, a thorough review of curricula should be conducted to ensure that learning materials and assessments are free from historical, medical, and societal stereotypes so that these biases are not perpetuated.

In summary, as universities seek to address diversity, an explicit commitment is needed to provide dedicated time in the curriculum for education on minority populations and diversity topics. These efforts should also extend beyond the classroom to address diversity issues in the faculty, staff, standardized patients, and university policies. Opportunities should be sought for institutions to partner with experts in the community who can share their knowledge, serve as speakers, and provide learning resources. Finally, these efforts can be facilitated as institutions provide students with a mechanism to report concerns about learning opportunities and to recommend suggestions for improvement.

\section{Drivers of Change}

\section{Paris Webb, D4 Student, Texas A\&M University College of Dentistry, USA}

In response to the COVID-19 pandemic, many institutions were forced to switch from a traditional in-class lecture model to a virtual educational format. These efforts demonstrated that virtual learning is possible, although it cannot substitute for the requisite face-to-face learning required to master communication and hand skills that dentistry requires. Thus, the pandemic has presented a unique opportunity to rethink how we educate health professions students.

Another driver of change at Texas A\&M College of Dentistry occurred in response to changes in the national dental board examination [3]. Specifically, the institution introduced several curricular changes to provide new educational approaches and assessments to prepare future dentists to excel in the evolving field of dentistry. These changes included reorganization of a siloed first-year curriculum into an integrated systems-based human structure, function, and pathology course that included content from anatomy, histology, physiology, biochemistry, and pathology. In addition, the creation of an integrated practice of dentistry course enabled firstyear students to practice diagnostic techniques as part of the physical assessment of the dental patient, which facilitated early entry of these students into the dental clinics to assist upper-level students. Third, a new longitudinal comprehensive pain management curriculum was developed in response to the ongoing opioid epidemic.

A final driver of change in healthcare education is the growing diversity of the US population [4], which highlights the importance of teaching students about cultural competence and social determinants of health in all specialties of healthcare including dentistry. These changes in healthcare education necessitate collaboration between students, educators, and institutions to ensure that the next generation of dental health professionals are well prepared to provide individualized patient care.

\section{Changes in a Dutch Dentistry Program to Cope with Changing Times}

\section{Koen den Brok, Master 2 (5th Year Student), Radboud University Medical Center, The Netherlands}

Over the years, the practice of dental care in the Netherlands has slowly changed due to an aging population with different healthcare demands [5]. At the same time, the number of oral health professionals is declining as many of them are facing retirement in the next 5-10 years. In response to these developments, dentists have begun to collaborate in shared practices and group-clinics [6].

To prepare the dental students of today for this new reality of the future, Radboud UMC Dental Faculty developed a Master Clinic program for 4-6th year students. This Master Clinic creates an interprofessional workplace simulating a dental clinic. In the Master Clinic, both dentistry and oral hygienist students learn practical and theoretical dentistry together while providing care to the patients in their respective clinics. Entrustable Professional Activities have been implemented as an effective tool to teach students selfreflection and to follow study progression on clinical and professional activities [7, 8]. Students also learn leadership skills as they are now involved in teaching their peers and managing the clinics. In the program, teachers have taken on the role of coaches and guides instead of lecturers. This novel approach is highly valued amongst students and staff and has proved to be a significant addition in preparing and motivating the students for life-long learning. This successful innovation could not have happened without synergy between student representatives and the faculty.

Finally, the COVID-19 epidemic has been an accelerator for the development and implementation of new digital teaching modalities in the dental curriculum. These new teaching modes have enabled students to learn at their own pace and have opened up possibilities for making the study program more flexible. These and other curricular changes have the potential to decrease stress felt by healthcare professions students and should be carried forward into the future. 


\section{Empathetic to the Situation, Dedicated to the Solution}

\section{Elizabeth Woodburn, M3 Student, Carle Illinois College of Medicine, USA}

The future of medical education should be forward-focused, patient-centered, and student-driven to graduate professionals who are engaged in their work and positioned to lead the field of healthcare forward. As students have access to an everincreasing amount of information in the form of texts and digital resources from which to learn the basic sciences, there is a need to refocus classroom time on collaborative learning and synthesis of information. With problem-based learning serving as an early foundation, students can translate learning to patient care and scholarship, so they are better stewards of healthcare resources [9]. Dedicated independent study time in the curriculum is needed for students to examine medicine from different perspectives and to devise potential solutions for clinical problems they encounter [10]. These changes will encourage students to embrace a growth mindset and create positive change. To achieve these goals, health science educators must also adopt a growth mindset and be open to developing and using novel interventions, methodologies, pedagogies, and learning tools.

\section{Compliance with Ethical Standards}

Conflict of Interest The authors declare that they have no conflict of interest.

Ethical Approval NA

Informed Consent NA

\section{References}

1. Glicksman E. Unconscious bias in academic medicine: overcoming the prejudices we don't know we have. 2018. https://www.aamc. org/news-insights/unconscious-bias-academic-medicineovercoming-prejudices-we-don-t-know-we-have. Accessed 3 June 2020.

2. Wittlin NM, Dovidio JF, Burke SE, Przedworski JM, Herrin J, Dyrbye L, et al. Contact and role modeling predict bias against lesbian and gay individuals among early-career physicians: a longitudinal study. Soc Sci Med. 2019;238:112422. https://doi.org/10. 1016/j.socscimed.2019.112422.

3. Examinations JCoND. Integrated National Board Dental Examination. https://www.ada.org/en/jende/inbde. Accessed 16 Sept 2020.

4. United States Census. https://data.census.gov/cedsci/profile?q= United\%20States \&g=0100000US.

5. Dossier Vergrijzing. https://www.cbs.nl/nl-nl/dossier/dossiervergrijzing. Accessed 17 Sept. 2020.

6. Waar bent u naar op zoek? https://www.staatvandemondzorg.nl. Accessed 14 Sept. 2020.

7. HCC OC, Hoff RG, Peters H, Bok H, van der Schaaf M. Curriculum development for the workplace using Entrustable Professional Activities (EPAs): AMEE Guide No. 99. Med Teach. 2015;37(11):983-1002.

8. Ten Cate OSA, Chen HC. Assessing trainees and making entrustment decisions: on the nature and use of entrustment-supervision scales. Acad Med. 2020;published online ahead of print, 2020 Apr 21. https://doi.org/10.1097/ACM.0000000000003427.

9. Neville AJ. Problem-based learning and medical education forty years on. A review of its effects on knowledge and clinical performance. Med Princ Pract. 2009;18(1):1-9. https://doi.org/10.1159/ 000163038 .

10. Coiado OC, Ahmad K. Introducing first-year medical students to product innovation and entrepreneurship. Med Sci Educ. 2019;30: 19-20.

Publisher's Note Springer Nature remains neutral with regard to jurisdictional claims in published maps and institutional affiliations. 